\title{
EVALUASI APAR DAN HIDRAN SEBAGAI UPAYA PENANGGULANGAN KEBAKARAN DI PT X
}

\author{
Mariska Hamid \\ Departemen Kesehatan dan Keselamatan Kerja, \\ Fakultas Kesehatan Masyarakat, Universitas Airlangga \\ Email: mariskahamidb@gmail.com
}

\begin{abstract}
APAR and hydrants are devices that are used as a tool to overcome small and large fires. The purpose of this study is to learn in general the description of the application of fire extinguishers and fire hydrants as fire prevention efforts at PT X. This research is a cross sectional approach and is a descriptive study. Variables in this study are APAR, Hydrant and Company Policy. The results of the study are that almost all APAR installations are in accordance with Permenakertrans No. PER. 04 / MEN / 1980 concerning the conditions for installing APAR. Most hydrant installations are also in accordance with Kepmen PU No. 02 / KPTS / 1985 concerning provisions for prevention and control of fires in buildings, but there are still 1 hydrant whose installation is covered by residual material and there is a hydrant box that does not have the word "Hydrant" in white. Companies are advised to pay attention to the installation of high APAR and review the installation of the hydrant box so that it is not obstructed by objects and give an white mark "Hydrant".
\end{abstract}

Keywords: Portable Fire Estingusher, Hydrant, Company policy

\begin{abstract}
ABSTRAK
APAR dan hidran adalah alat yang digunakan sebagai alat untuk menanggulangi di saat terjadinya kebakaran kecil dan besar. Tujuan Umum dari penelitian ini adalah memepelajari secara umum gambaran penerapan APAR dan hidran sebagai upaya penanggulangan kebakaran di PT X. Penelitian ini adalah penelitian dengan pendekatan cross sectional dan merupakan penelitian deskriptif Variabel pada penelitian ini ialah APAR, Hidran dan Kebijakan Perusahaan. Hasil pada penelitian adalah hampir semua pemasangan APAR telah sesuai dengan Permenakertrans No. PER. 04/MEN/1980 tentang syarat-syarat pemasangan APAR. Sebagian besar instalasi hidran juga sudah sesuai dengan Kepmen PU No. 02/KPTS/1985 tentang ketentuan pencegahan dan penanggulangan kebakaran pada bangunan gedung, namun masih terdapat 1 hidran yang pemasangannya tertutup oleh material sisa dan terdapat box hidran yang tidak memiliki tulisan "Hydrant" berwarna putih. Perusahaan disarankan untuk memperhatikan pemasangan tinggi APAR dan meninjau ulang pemasangan box hidran agar tidak terhalang oleh benda dan memberikan tulisan "Hydrant" dengan warna putih.
\end{abstract}

Kata kunci: APAR, Hidran, Kebijakan Perusahaan 


\section{PENDAHULUAN}

Kebakaran merupakan kejadian yang dapat menyebabkan kerugian pada jiwa, peralatan produksi, proses produksi, pencemaran lingkungan kerja, dan khususnya pada peristiwa kebakaran yang besar sehingga dapat melumpuhkan bahkan menghentikan proses usaha, sehingga dapat menyebabkan kerugian yang sangat besar. ${ }^{1}$

Berdasarkan Undang-undang Republik Indonesia Nomor 1 tahun 1970 tentang keselamatan kerja tentang syarat-syarat keselamatan kerja pasal 3 "syarat-syarat keselamatan kerja untuk mencegah dan mengurangi kecelakaan, mencegah, megurangi dan memadamkan kebakaran dan mencegah dan mengurangi bahaya peledakkan". Kasus kebakaran yang sering terjadi di PT X yang disebabkan oleh salah satu proses produksi di salah satu unit pembakaran yaitu bagian furnace ketika proses baru dimulai sehingga tindakan pencegahan dapat diterapkan agar tidak terjadinya kebakaran dengan cara mengeleminasi atau mengendalikan berbagai bentuk perwujudan energi yang digunakan. salah satu tindakan pencegahan yang dapat dilakukan terhadap terjadinya bahaya kebakaran yang dapat terjadi di tempat kerja adalah dengan menyediakan Alat pemadam api ringan dan fire hidrant. Pemasangan APAR ialah sebuah tindakan awal pada penanggulangan kebakaran sebelum kebakaran menjadi besar. sedangkan Fire hidrant adalah peralatan yang digunakan di saat kebakaran mulai membesar dan tidak bisa ditangani lagi oleh APAR.

Untuk menunjangnya tindakan penanggulangan dan pencegahan yang handal dan baik, maka diperlukannya penerapan APAR dan hidrant yang baik dan sesuai dengan peraturan yang berlaku sehingga penggunaan dapat berjalan dengan maksimal dan baik.

Berjalan dengan baiknya penerapan APAR dan hidrant disuatu perusahaan dapat membuat perusahaan siap menghadapi suatu peristiwa kebakaran yang dapat terjadi kapan saja dan dimana saja. dan juga dapat mengurangi konsekuensi yang berdampak dengan kerugian yang dapat terjadi di perusahaan.

\section{METODE PENELITIAN}

Ditinjau dari segi waktu, penelitian ini termasuk cross sectional karena penelitian dilakukan dalam kurun waktu tertentu. Menurut rancang bangun penelitian penelitian ini adalah penelitian deskriptif observasional yaitu penelitian yang bertujuan untuk memepelajari penerapan APAR dan hidran sebagai upaya penanggulanagan kebakaran dan menurut tempatnya penelitian ini termasuk penelitian lapangan. Obyek penelitian ini yaitu penerapan Apar dan Hidran di X. Pengelompokkan data primer dilakukan dengan cara observasi dan wawancara, lalu data pendukung yakni data sekunder diperoleh dari perusahaan atau dari data yang sudah ada di tempat kerja maupun dari sumber lain yang berasal dari kepustakaan. 


\section{HASIL DAN PEMBAHASAN}

\section{Alat Pemadam Api Ringan}

Berdasarkan hasil wawancara dengan karyawan departemen Enviroment Health and safety, PT. X telah dilengkapi oleh 178-unit Alat Pemadam Api Ringan, dimana terdapat 2 warna APAR yaitu APAR berwarna merah dan juga APAR berwarna hijau dengan berat yang berbeda-beda.

Tabel 1. Warna APAR dan Berat APAR di PT.X

\begin{tabular}{lll}
\hline No & Warna APAR & Berat APAR $(\mathrm{kg})$ \\
\hline 1 & Merah & $2,3,6,9,25$ dan 45 \\
\hline 2 & Hijau & 6 dan 9 \\
\hline
\end{tabular}

\section{Pemasangan Alat Pemadam Api Ringan}

Terdapat 4 lokasi dalam pemasangan APAR yang terdapat di PT X, berikut penjelasan lokasi peletakaan APAR dan Jenis media pemadam yangh ada di PT X.

Tabel 2. Lokasi, Jumlah APAR dan Jenis Media APAR

\begin{tabular}{crc}
\hline Lokasi & $\begin{array}{c}\text { Jumlah } \\
\text { APAR }\end{array}$ & Jenis Media Pemadam \\
\hline $\mathrm{A}$ & 97 unit & DCP \& $\mathrm{CO}_{2}$ \\
\hline $\mathrm{B}$ & 63 unit & DCP \& CO \\
\hline $\mathrm{C}$ & 13 unit & DCP \& CO 2 \\
\hline $\mathrm{D}$ & 5 unit & DCP \& $\mathrm{CO}_{2}$
\end{tabular}

Sebanyak 178-unit APAR yang dipasang di PT X menggantung pada tiang kolom dan diletakkan pada tempat penyanggah. Tinggi Pemasangan tanda APAR $125 \mathrm{~cm}$ dari lantai. Tanda APAR berbentuk segitiga sama sisi juga dipasangan disetiap tempat terdapatnya APAR dengan warna segitiga merah dan tulisan berwarna putih. Selain tanda APAR terdapat juga kartu pemerikasaan APAR yang dipasang pada setiap APAR yang berisi tanggal pemeriksaan APAR, isi APAR, dan Tanda tangan petugas pemeriksa APAR.

\section{Kesesuaian Apar}

Tabel 3. Kesusai APAR PT X

\begin{tabular}{lcc}
\hline Lokasi & $\begin{array}{c}\text { Pemasangan } \\
\text { APAR yang } \\
\text { Sesuai }\end{array}$ & $\begin{array}{c}\text { Pemasangan } \\
\text { APAR yang } \\
\text { Tidak Sesuai }\end{array}$ \\
\hline A & 74 & 23 \\
\hline B & 57 & 6 \\
\hline C & 13 & - \\
\hline D & 5 & - \\
\hline Jumlah & 149 & 29 \\
\hline
\end{tabular}

Berdasarkan hasil observasi didapati 29 APAR yang tidak dipasang dengan digantung pada tinggi $120 \mathrm{~cm}$, namun 29 APAR tersebut dipasang dengan langsung bersentuhan dengan lantai tanpa adanya pembatas ataupun penyanggah dan juga terdapat 1 APAR yang tidak terdapat kartu pemasangan APAR.

Berdasarkan hasil observasi Tanda segitiga yang memiliki ukuran $35 \mathrm{~cm}$ x $35 \mathrm{~cm}$ juga sudah dipasang dengan baik didekat tempat APAR diletakkan.

\section{Pemeliharaan Apar}

$$
\text { Menurut Permenakertrans No: }
$$

PER.04/MEN/1980 tentang syarat-syarat pemasangan dan Pemeliharaan Alat Pemadam Api Ringan pasal 11 ayat 1 bahwa seluruh APAR wajib di cek minimal 2 kali dalam setahun, ialah pengecekan pada jangka 6 (enam) bulan dan pemeriksaan dalam jangka 12 (dua belas) 
bulan. Berdasarkan hasil wawancara dengan karyawan SHE. pemeliharaan APAR dilaksanakan setiap 1 bulan sekali yaitu pada setiap minggu pertama disetiap bulannya. Hal ini bertujuan untuk mengetahui kondisi dan isi dari setiap APAR yang ada dan selalu dalam kondisi siap untuk digunakan dalam upaya penanggulanagan kebakaran yang dapat kapan saja terjadi. Pemeliharaan APAR dilakukan oleh karyawan depertemen Environment Health and Safety PT X. Pemeriksaan Alat pemadam Api Ringan (APAR) setiap 1 bulan dilakukan dengan media bantu berupa checklist yang digunakan untuk mempermudah petugas dalam melakukan pemeriksaannya, bagian-bagian yang di periksa meliputi:

1. Condition/Pressure

2. Gauge

3. Segel

\section{Exire Date}

Selain pemeriksaan kondisi fisik pada APAR, petugas juga melakukan pembersihan dan pengisian kartu pemeriksaan APAR.

\section{Kondisi Fisik Apar}

Sebanyak 178-unit APAR yang terdapat di PT $X$ memiliki kondisi yang baik. Berdasarakan observasi yang telah dilakukan tidak ditemui APAR dengan fisik berkarat, semua safety pin terpasang, peletakan APAR yang mudah dijangkau dan mudah terlihat dan tidak ditemuinya APAR yang melewati batas masa kadaluarsa. Pada Setiap APAR terdapat sticker putih yang bertuliskan bahwa APAR telah siap pakai dari tanggal hingga tanggal yang telah ditentukan oleh perusahaan yang melakukan pengisian APAR. Masa kadaluarsa APAR sekitar 4 tahun.

\section{Kartu Pemasangan Apar}

Kartu pemasangan APAR Adalah suatu kartu yang dipasang menggantung pada leher Alat Pemadam Api Ringan berisi tentang informasi kapan Alat Pemadam Api Ringan ini di periksa, bagaimana keadaan isi tabung dan siapa orang yang melakukan pemeriksaan. Berdasarkan hasil observasi yang ada semua kartu pemasangan Alat Pemadam Api Ringan telah diisi dengan lengkap dan benar namun ditemukan 1 Alat Pemadam Api Ringan yang tidak memiliki kartu pemasangan Alat Pemadam Api Ringan.

\section{Instalasi Hydrant}

PT X memiliki 1 jenis hidran yaitu hidran halaman yang terletak diberbagai titik lokasi perusahaan. Berdasarakan hasil wawancara dengan karyawan departemen HSE terdapat 19unit hidran pilar dan hidran box yang berjenis hidran halaman yang dilengkapai dengan nozzle, selang dan kunci pembuka. Kopling yang digunakan oleh PT X adalah kopling berjenis Machino.

Sumber air di PT $\mathrm{X}$ bersumber dari air sumur yang ditampung, kemudian diolah oleh divisi Water Treatment Plant (WTP) dan disebarkan untuk memenuhi pasokan air hidran yang terdapat di PT X. Air yang dihasilkan tersebut tidak semuanya digunakan untuk 
sumber persediaan hidran namun juga digunakan sebagai air untuk bahan proses produksi dan juga air untuk menjalankan boiler. Kapasitas tangki untuk hidran yang ada di PT X sendiri ini memiliki kapasitas $250 \mathrm{~m}^{3}$. Untuk mengalirkan air dari WTP ke seluruh instalasi hidran yang ada pihak PT X menggunakan pompa dengan spesifikasi sebagai berikut:

\section{Putaran mesin : $2950 \mathrm{rpm}$}

2. Kapasitas $: 170 \mathrm{~m}^{3} / \mathrm{jam}$

3. Tenaga/ Power : $100 \mathrm{HP}$

Berdasarkan spesifikasi pompa diatas jenis pompa yang ada di PT X hanya berjenis main pump tanpa adanya pompa yang berjenis jockey pump dan diesel pump, dimana kedua pompa tersebut digunakan untuk memompa air untuk pasokan hidran pada saat kondisi darurat.

\section{Pemeliharaan Hydrant}

Pemeriksaan atau pemeliharaan hidran dilakukan secara berkala sangat diperlukan untuk memperisiapkan keadaan hidran pada saat digunakan pada terjadinya kebakaran, hal ini adalah sebuah tindakan yang dapat dilakukan dalam rangka upaya mengurangi tingkat keparahan risiko kerugian dari segi jiwa maupun aset.

Pemeliharaan instalasi hidran di PT X dilakukan secara berkala setiap satu bulan sekali hal ini sudah sesuai dengan Kepmen PU No.02/KPTS/1985 tentang pencegahan dan penanggulangan kebakaran pada bangunan gedung pada pasal 38 yaitu perangkat pencegahan dan penanggulangan kebakaran yang dipasang pada bangunan gedung dan lingkungannya seperti tersebut pada pasa 17 ayat 2, wajib di cek berkala oleh petugas yang mempunyai tugas untuk menjamin keaadaan masing-masing alat tersebut agar dapat berfungsi secara efektif saat terjadi kebakaran.

\section{Kondisi Fisik Hidran}

Berdasarkan hasil observasi yang ada dilapangan 19 unit atau semua hidran box hidran yang terdapat di PT X sudah dilengkapi dengan selang, nozzle dan kunci, Hal ini berarti sudah sesuai dengan kepmen PU No.02/KPTS/1985 tentang pencegahan dan penaggulangan kebakaran pada bangunan gedung yaitu Hydrant Box harus berisi selang, nozzle dan kunci pembuka.

Semua box hidran yang ada di PT X telah dicat dengan berwarna merah, berdasarkan hasil observasi terdapat 6 unit box hidran nomor 1, 3, 4, 5, 13 dan 16 yang tidak terdapat tulisan HYDRANT berwarna putih hal ini tidak sesuai karena seharusnya box hidran diberi tulisan berwarna putih.

Dengan demikian seharusnya perusahaan melakukan perbaikan atau pengecatan terkait tulisan HYDRANT berwarna putih pada box hidran.

\section{SIMPULAN DAN SARAN}

\section{Simpulan}

1. Belum terdapatnya kebijakan perusahaan tentang penanggulangan bahaya, namun sudah terdapatnya Work Instructure dan 
telah dibentuknya tim penanggulangan bahaya di PT X.

2. Pemasangan APAR sudah sesuai dengan Peraturan Menteri Tenaga Kerja dan Transmigrasi No.: PER/04/MEN/1980 tentang syarat-syarat pemasangan dan pemeliharaan alat pemadam api ringan, namun masih terdapat 29-unit APAR yang tidak diletakkan pada posisi $120 \mathrm{~cm}$.

3. Pemeliharaan Alat Pemadam Api Ringan sudah sesuai dengan Peraturan Menteri Tenaga Kerja dan Transmigrasi No.: PER/04/MEN/1980 tentang syarat-syarat pemasangan dan pemeliharaan alat pemadam api ringan.

4. Kondisi Fisik APAR sudah sesuai dengan Menteri Tenaga Kerja dan Transmigrasi No.: PER/04/MEN/1980 tentang syaratsyarat pemasangan dan pemeliharaan alat pemadam api ringan, karena tidak ada APAR dengan keadaan berlubang atau cacat karena karat.

5. Pemasangan hidran sudah sesuai dengan keputusan Menteri Pekerjaan Umum No.02/KPTS/1985 tentang ketentuan pencegahan dan penaggulangan kebakaran pada bangunan, namun masih terdapat 1unit hidran yang pemasangannya masih terhalang oleh benda lain.

6. Pemeliharaan hidran sudah dilakukan secara berkala setiap 1 bulan sekali sesuai dengan keputusan Menteri Pekerjaan Umum No.02/KPTS/1985 tentang ketentuan pencegahan dan penaggulangan kebakaran pada bangunan gedung.

7. Kondisi fisik hidran sudah baik dan telah sesuai dengan keputusan Menteri Pekerjaan Umum No.02/KPTS/1985 tentang ketentuan pencegahan dan penaggulangan kebakaran pada bangunan karena isi box hidran telah terisi lengkap.

\section{Saran}

1. Membuat kebijakan umum perusahaan yang berisi tentang kebijakan K3 yang terdapat kebijakan tentang tanggap darurat didalamnya.

2. Pemasangan APAR seharusnya diletakkan menggantung pada tinggi tidak lebih dari $120 \mathrm{~cm}$ dari lantai sesuai dengan Peraturan Menteri Tenaga Kerja dan Transmigrasi No.: PER/04/MEN/1980 tentang syaratsyarat pemasangan dan pemeliharaan alat pemadam api ringan.

3. Pemberian 3 pompa pada perusahaan yaitu jockey pump, main pump dan diesel pump.

4. Pemberian kartu tanda pemasangan APAR pada setiap APAR yang terpasang di lingkungan PT X.

5. Pemasangan hidran seharusnya ditempat yang mudah dijangkau.

6. Pemberian tulisan "HYDRANT" yang bercat kan putih pada setiap box hidran yang terdapat di linkungan PT X agar hidran mudah dilihat dengan jelas. 


\section{REFERENSI}

1. ILO. Keselamatan dan Kesehatan Kerja Sarana Untuk Produktivitas. Jakarta. International Labour Office. 2103.

2. Ramli, S. Petunjuk Praktik Manajemen Kebakaran (Fire Management). Jakarta. PT Dian Rakyat. 2010.

3. Rijanto, B. Kebakaran dan Perencanaan Bangunan. Jakarta. Mitra Wacana Media. 2010.

4. Depnaker, RI. Trainning Material K3 bidang penanggulangan Kebakaran. Pusat Pendidikan dan pelatihan Pegawai.

5. Keputusan Menteri Negara Pekerjaan Umum No: 10/KPTS/2000 Tentang Ketentuan Teknis Pengamanan Terhadap Bahaya Kebakaran Pada Bangunan Gedung dan Lingkunga

6. Keputusan Menteri Pekerjaan Umum No. 02/KPTS/1985 Tentang Ketentuan Pencegahan dan Penanggulangan Kebakaran pada Bangunan Gedung

7. Keputusan Menteri Tenaga Kerja dan transmigrasi No. 04/MEN/1980 tentang Syarat-Syarat Pemasangan dan Pemeliharaan Alat Pemadaman Api Ringan.

8. Wahyudi, S. Bahan Kuliah Pencegahan Bahaya Kebakaran dan Alat Pemadam Apo Portabel. Gresik: Departemen Keamanan Kawasan PT Petrokimia Gresik. 2005. 